\title{
Transformações no mundo laboral e novos desafios do sindicalismo português
}

Elísio Estanque e António Casimiro Ferreira

\section{(2) OpenEdition}

Edição electrónica

URL: http://journals.openedition.org/rccs/1315

DOI: $10.4000 /$ rccs. 1315

ISSN: 2182-7435

Editora

Centro de Estudos Sociais da Universidade de Coimbra

\section{Edição impressa}

Data de publição: 1 Junho 2002

Paginação: 151-159

ISSN: 0254-1106

\section{Refêrencia eletrónica}

Elísio Estanque e António Casimiro Ferreira, «Transformações no mundo laboral e novos desafios do sindicalismo português », Revista Crítica de Ciências Sociais [Online], 62 | 2002, colocado online no dia 01 outubro 2012, criado a 30 abril 2019. URL : http://journals.openedition.org/rccs/1315 ; DOI :

$10.4000 /$ rccs. 1315 


\section{ELÍSIO ESTANQUE ANTÓNIO CASIMIRO FERREIRA}

Faculdade de Economia da Universidade de Coimbra e Centro de Estudos Sociais

\section{Transformações no mundo laboral e novos desafios do sindicalismo português}

O problema da transformação das relações laborais tem necessariamente de ser discutido à luz do actual contexto de globalização económica para que se compreendam as consequências deste processo para o movimento sindical e os novos desafios que este tem hoje pela frente.

Como se sabe, a economia mundial assentou desde sempre em múltiplos desequilíbrios entre centros e periferias. Mas, hoje, os contrastes entre pólos de desenvolvimento e zonas de exclusão e de miséria não só assumem contornos particularmente chocantes em países de rápido crescimento económico, onde as novas tecnologias convivem lado a lado com relações laborais de neo-escravatura (por exemplo, no Sudeste asiático), como no próprio seio dos países considerados avançados. Não há dúvida de que a inovação tecnológica e a revolução informática constituíram poderosos meios em que se apoiou o mercantilismo dos anos 80 para promover a desregulamentação da velha relação salarial fordista. Como consequência disso, assistiu-se a uma acentuada perda de peso do trabalho industrial nas sociedades avançadas (em especial na Europa), o que contribuiu para a crescente heterogeneidade e des-standardização das formas tradicionais de trabalho. Contudo, se a terciarização e a rápida expansão das novas tecnologias da informação promovem novas oportunidades para certos segmentos sociais, tais processos tendem a esconder os efeitos perversos que daí resultam sobre outros segmentos, arrastados para situações de maior precarização e exclusão, inclusive nas economias mais dinâmicas da União Europeia.

A visão idílica, neutra e fictícia de uma globalização homogeneizante e harmoniosa, que tem vindo a ser construída pelos ideólogos do neoliberalismo e pelos mass media ao seu serviço é diariamente negada pelos problemas laborais a nível mundial. O novo liberalismo global entrou numa dinâmica vertiginosa, e os seus impactos sobre as relações de trabalho fazem-se 
hoje sentir em todas as regiões do globo, a mostrar que a globalização não é propriamente uma imensa nuvem de fluxos a pairar sobre os poderes políticos e económicos que comandam o sistema mundial. É, pois, necessário atentar na sua materialidade concretizada em contextos particulares e situações sociais e humanas palpáveis e espacialmente vinculadas. A globalização é complexa e polimórfica, visto que as múltiplas interacções e impactos a que os mecanismos globais dão lugar adquirem as mais diversas especificidades e configurações em diferentes regiões e contextos espaciais, ou seja, os processos de globalização arrastam consigo novas formas de "localização".

Estamos hoje perante um novo modelo laboral e social, caracterizado pelo aumento da individualização das relações sociais, da insegurança, da precarização e do risco em diferentes níveis da vida social, nomeadamente na esfera laboral (Beck, 1992, 2000). A constante mobilidade do capital e o consequente aumento da fragmentação, a descentralização do processo produtivo, traduzem-se cada vez mais em fenómenos como a deslocalização de empresas, subcontratação, flexibilidade de horários, desemprego e emprego precário, etc., cujas consequências, apesar da larga margem de imprevisibilidade, já se fazem sentir de forma drástica sobre a actividade sindical. Acresce que, com o desmoronamento do império soviético, desfez-se em ar a velha ortodoxia comunista, que durante mais de um século serviu de modelo ideológico ao movimento operário, o que veio contribuir para o progressivo declínio em que entrou o sindicalismo "de classe", ao longo das últimas duas décadas.

Como é sabido, o movimento sindical tende a deixar de ser predominantemente de base operária, à medida que as sociedades se terciarizam, e esta é uma tendência que se verifica também em Portugal. Mas importa ter presente o papel histórico do movimento operário, visto que foi ele que, pelo menos até aos anos sessenta - e, no caso português, até um período mais recente -, alimentou as bases sociais do sindicalismo e essa referência e essa memória continuam a marcar o discurso e as propostas de acção de uma larga corrente do sindicalismo português. Podemos dizer que esta concepção continua a apoiar-se numa visão do mundo laboral fixada nas velhas contradições de classe, herdada do marxismo estruturalista que hegemonizou o discurso público em Portugal no pós-25 de Abril de 1974. Todavia, é hoje quase unanimemente reconhecido que esta visão deixou de adequar-se à realidade social do mundo actual. Ou seja, muito embora as classes sociais estruturadas a partir da esfera produtiva continuem a fornecer a principal base das desigualdades, o certo é que, como quase todos os estudos comprovam (Wright, 1985, 1997; Pakulsky e Waters, 1996; Estanque e Mendes, 1998), a classe deixou há muito de ser o determinante principal 
do conflito político. Num quadro de crescente globalização e individualização das relações sociais as clivagens de classe produzem simultaneamente antagonismos de interesses e relações de consentimento a partir da produção, sejam elas fundadas em regimes de tipo hegemónico ou de tipo despótico (Burawoy, 1985). Se, até aos anos sessenta, a luta de classes conduzida pelo movimento operário nos países industrializados teve um amplo significado social e político, foi porque havia condições para construir culturas operárias fortes, sob a forma de comunidades de resistência ou emancipatórias, as quais entretanto se esbateram ou se extinguiram por completo. O tradicional sistema de produção taylorista e o modelo de regulação fordista começaram a cindir-se e a fragmentar-se, fazendo emergir formas de trabalho mais desreguladas e inseridas num quadro social mais marcado pela terciarização do emprego e pela expansão dos consumos de massa.

Evidentemente que, a par da perda de vitalidade deste modelo de acção sindical, centrado na mobilização operária - sobretudo à medida que se assiste ao crescimento do sector terciário na população activa - cresceu também a sindicalização dos trabalhadores dos serviços administrativos e do funcionalismo público, bem como a presença dos sindicatos nos mecanismos de concertação. Isto fez com que, nuns casos de forma mais aberta, noutros apenas implicitamente, as estruturas sindicais passassem a integrar cada vez mais as instâncias de regulação institucional, negociando com o Estado e os restantes parceiros sociais a definição das políticas laborais e sociais. Estas circunstâncias conferiram ao movimento sindical um novo papel no desenhar das grandes reformas sociais, reforçando o seu protagonismo institucional, mas, ao mesmo tempo, retirando-lhe parte da sua capacidade de mobilização. A este propósito, poderá dizer-se que, ao longo das últimas décadas, as conquistas dos trabalhadores e do movimento sindical tradicional cederam, na prática, às pressões da lógica cooptativa, entrando sem o perceber na dinâmica do sistema, ou seja, deixando-se absorver pela lógica de regulação (Santos, 2000: 335). Não só o capitalismo conseguiu em parte "canibalizar" as lutas da classe trabalhadora, como até as estruturas dirigentes dos principais sindicatos se tornaram, em certa medida, instrumentos da acção reguladora do Estado.

Convém, no entanto, não esquecer que, lado a lado com as tendências de desacreditação do "velho" sindicalismo de base operária e nacional, diversos sinais de renovação - sobretudo no plano das ideias e do debate político - têm vindo a surgir, tanto no campo académico como no domínio sindical, apontando para a emergência de um "novo" movimento social sindical de âmbito global ou internacional (Moody, 1997; Bezuidenhout, 1999; Ashwin, 2000; Estanque, 2002). Estamos em crer que este processo 
de revitalização será cada vez mais visível no futuro próximo, já que o movimento sindical se mostra hoje mais aberto e reconhece explicitamente a necessidade de renovar os seus métodos e estratégias de actuação perante a força crescente do capitalismo global.

É a partir destas linhas de orientação que concebemos as novas complexidades e desafios a que os sindicatos procuram hoje responder. Daí que as questões que decidimos abordar no presente dossier tenham sido concebidas no sentido de clarificar, em diálogo directo com os dirigentes das duas principais centrais sindicais portuguesas (a CGTP-IN e a UGT), muitos dos problemas que acabámos de identificar. O nosso objectivo vai, portanto, no sentido de conhecer mais de perto as suas experiências recentes, as reflexões internas e as estratégias de cada uma destas duas grandes correntes do movimento sindical no nosso país. As seis questões que colocámos aos nossos interlocutores poderão ser agregadas em dois grandes campos: a) o primeiro, em torno das propostas e formas de actuação no terreno, isto é, no plano da organização e mobilização dos trabalhadores; e b) o segundo, relativo às propostas e formas de intervenção no plano dos mecanismos de negociação e relações institucionais que as estruturas sindicais mantêm com o Estado e os restantes parceiros sociais. Qualquer deles parece-nos fundamental para se perceber a profundidade das mudanças em curso no campo sócio-laboral e as respostas que as estruturas sindicais vêm procurando construir. Por esse motivo, vale a pena discutir, ainda que de forma abreviada, cada uma destas duas problemáticas.

Quanto ao primeiro conjunto de questões, o objectivo foi confrontar os dirigentes sindicais com problemas como a tendencial fragilização do sindicalismo, a construção das redes transnacionais e a segmentação das condições de trabalho. São conhecidos resultados de diversos estudos que comprovam o aumento da desfiliação e a crescente dificuldade de organizar e mobilizar os trabalhadores a partir das empresas (Cerdeira, 1997; Ferreira, 2001). Como resultado da crescente competitividade económica dos mercados globais, e sobretudo se tivermos em conta o seu impacto em países pouco competitivos em termos tecnológicos, como Portugal, a lógica empresarial continua a funcionar, em larga medida, segundo modelos tradicionalistas - em especial no sector industrial - e orientados para a contenção dos custos salariais, para a persistência dos baixos salários como resposta ao aumento da concorrência. Perante uma legislação laboral considerada pelos empresários demasiado proteccionista do trabalhador, procurou-se desenvolver um modelo de flexibilização que passa, antes de mais, por encontrar expedientes para contornar a lei, recorrendo-se a formas de subcontratação de trabalho, por vezes clandestinas, ao trabalho domiciliário, aos contratos a 
prazo, etc., o que conduz a uma fraca efectividade do direito laboral dentro das empresas, especialmente nas de pequena e média dimensão. Esta situação traduz-se no progressivo aumento de formas de trabalho precário que colocam o trabalhador numa maior dependência do empregador e inibem na prática a sua participação sindical. Paralelamente a isto, há, como é evidente, toda uma série de transformações que vêm ocorrendo na sociedade, como o apelo ao consumo, o aumento da insegurança das pessoas, $o$ acentuar do individualismo, aspectos que tendem a empurrar o cidadão comum para uma vida mais resguardada na esfera privada, o que, sobretudo nos grandes centros urbanos, se traduz no acentuar do isolamento e da solidão e faz aumentar o défice de cidadania e de participação na vida colectiva.

As propostas recentes de Peter Waterman chamam justamente a atenção para a necessidade de uma reconceptualização do velho internacionalismo sindical no sentido de adequá-lo à actual era do capitalismo das redes globais informatizadas. ${ }^{1}$ Algumas destas orientações já estavam, de resto, presentes nas teses sobre o sindicalismo português, apresentadas em 1995 por Boaventura de Sousa Santos. Salientando a importância do princípio da solidariedade, como resposta necessária ao crescente reforço das regulações locais e transnacionais em prejuízo dos mecanismos nacionais de regulação, o autor postulava que a construção de uma cidadania activa passaria pela combinação entre um maior envolvimento directo do sindicalismo no espaço da produção (nomeadamente através do reforço do papel das comissões de trabalhadores) e uma maior intervenção fora do espaço da produção, devendo esta articular-se com "outros movimentos sociais progressistas, movimentos de consumidores, feministas, etc. [...], as energias contestatárias do movimento sindical devem ser deslocadas para a articulação com estes outros movimentos" (Santos, 1995: 135). Na verdade, os chamados Novos Movimentos Sociais introduziram toda uma série de novos contributos, no campo das propostas políticas, dos temas em debate, nas linguagens e formas de participação pública. Além de terem alargado o leque da conflitualidade social para esferas exteriores à produção - a luta pela paz, o ambientalismo, a emancipação da mulher, os direitos dos consumidores, os direitos humanos, etc. -, o seu crescente protagonismo entrou, de certa forma, em concorrência com as velhas formas de luta de classes fundadas na acção operária.

Quanto ao segundo conjunto de questões, estão em causa dois eixos estruturantes da agenda político-laboral da actualidade. O primeiro radica na

${ }^{1}$ Veja-se o artigo de Peter Waterman, publicado neste volume. 
possibilidade desejável de compatibilizar justiça social na esfera laboral com produtividade e crescimento económico. Esta é uma questão condicionada, como já se referiu, pela circunstância de nos sistemas de relações laborais coexistirem modelos de organização do trabalho e condições de trabalho dispares, neles se reconhecendo por um lado, o taylorismo tradicional, e por outro, o "admirável mundo novo" da sociedade do conhecimento e da informação. Da combinação entre a lógica taylorista e o modelo de desenvolvimento económico-social, assente nos baixos salários como factor competitivo, resulta a indiferença aos desafios colocados pela introdução de novas tecnologias, o aumento da qualificação das pessoas e a requalificação profissional. O fosso entre estes dois modelos é enorme, dele se encontrando ilustração às escalas global, nacional e sectorial. O desafio está em não se estabelecer como objectivo apenas o acesso ao mercado de trabalho e à criação de empregos, mas pugnar pela defesa do acesso a um trabalho com qualidade, exercido em condições dignas, baseado na aprendizagem, no conhecimento e na formação ao longo da vida. As relações entre formação, conhecimento e qualidade de vida estão há muito estabelecidas. Refira-se como exemplos o investimento do Estado e das empresas na prevenção dos riscos profissionais e formação dos trabalhadores, correspondendo a uma redução dos acidentes de trabalho e doenças profissionais, a compatibilização entre a vida familiar e a vida profissional, concorrendo para a elevação das expectativas sociais e da auto-estima dos cidadãos trabalhadores. Ainda neste domínio, a formação e qualificação profissionais são indissociáveis do aumento da produtividade e da competitividade das empresas. Enquadrada pelas preocupações a que temos aludido, a discussão em torno da adaptação dos trabalhadores e do ajustamento e modernização das empresas poderá ser compaginável com o aumento da equidade e justiça sociais no mundo do trabalho. É também por esta via que as relações laborais poderão, numa perspectiva emancipatória, transformar-se de relações de subordinação em relações de autoridade partilhada, (re)democratizando-se assim o espaço da produção.

O segundo eixo remete para uma das características constitutivas dos sistemas de relações laborais nas sociedades democráticas: a negociação e o diálogo social. Em certo sentido, os modernos sistemas de relações laborais são o resultado de um processo iniciado durante o século XIX, através do qual se foram criando as fórmulas de negociação entre trabalhadores e empregadores com maior ou menor interferência do Estado. Com efeito, um longo caminho foi percorrido, desde a fase de repressão dos trabalhadores e suas organizações, passando pela fase de reconhecimento, até chegarmos aos modelos paradigmáticos de negociação colectiva instituídos no 
pós-guerra ou, mais recentemente, com os exemplos de concertação e de diálogo social, induzidos pelo modelo social europeu e pelo carácter tripartido da OIT.

Como salientam Richard Hyman (neste volume) e Boaventura de Sousa Santos (2000), a regulação das relações de trabalho assenta num complexa dinâmica sociológica, na qual são activadas diferentes formas de regulação. A tensão entre o status e o contrato ou a combinação entre os princípios sócio-políticos do Estado, do mercado e da comunidade estão presentes em graus e modalidades diversas em todos os sistemas de relações laborais. Neste sentido, os espaços e contextos da negociação e do diálogo social revestem-se de uma autonomia relativa, cuja margem de liberdade é balizada pela capacidade de interferência de princípios de regulação hegemónicos, nomeadamente, os do mercado e do Estado. Para não ser mera miragem política nem equívoco auto-regulatório, o diálogo social tem de fazer parte do debate democrático e contribuir para o aprofundamento da democracia laboral e da efectividade das normas laborais. Para ser democrático, tem de emergir de relações sociais, organizacionais e institucionais bipartidas ou tripartidas, em que o poder das partes é política e socialmente equilibrado. Não o sendo, a co-responsabilização na produção e aplicação das matérias consensualizadas transforma as oportunidades de uns nos riscos de outros.

A transversalidade do diálogo social faz-se acompanhar, quer das tendências de "desnacionalização" dos sistemas de relações laborais, balizadas pela hipótese de constituição de um sistema europeu de negociação colectiva e concertação social, quer da descentralização da negociação para o nível das empresas. Combinado com boas práticas, o diálogo social é elemento nuclear do modelo social europeu, reconhecendo-se, por exemplo, na constituição dos conselhos de empresa europeus, nas directivas sobre informação, participação e consulta dos trabalhadores, ou ainda nas recentes discussões sobre a responsabilidade social das empresas. Também ao nível transnacional, a necessidade de uma regulação global do trabalho tem conduzido a OIT à promoção activa das formas de negociação e do diálogo, como elemento de um trabalho digno. No entanto, e para além da visível necessidade de rever o projecto OIT, fica a dúvida de saber se a dimensão social da globalização, onde o diálogo social transnacional é acolhido, terá alguma potencialidade emancipatória no confronto com o consenso neoliberal hegemónico, onde o trabalho continua a ser encarado como uma mercadoria.

Situadas as grandes linhas de problematização que decidimos estabelecer para este dossier, disponibilizamos agora aos nossos leitores duas abordagens sobre o sindicalismo português, que expressam ao mesmo tempo duas experiências distintas de participação e envolvimento nos problemas do 
mundo laboral e institucional. Mais do que um mero registo biográfico, estão em causa a história recente do país e as histórias que cada um destes protagonistas traz na bagagem. A partilha do passado influencia a acção no presente e a disponibilidade para pensar o futuro, mas as próprias condições em que decorre a acção definem-lhe os parâmetros de (re)criação do pensamento face aos desafios que têm de enfrentar. Para nós, permanece em aberto a questão de saber se são os sujeitos que fazem a história ou se é antes a história que produz os sujeitos. O mais provável é que ambos os processos ocorram em simultâneo. Sendo os actores indissociáveis dos sistemas estruturados em que operam, o relevo dos testemunhos apresentados deriva da combinação entre as vivências que nos legam e as perspectivas que nos propõem.

\section{Referências Bibliográficas}

Ashwin, Sarah (2000), "International Labour Solidarity after the Cold War", in Robin Cohen; Shirin Rai (orgs.), Global Social Movements. London: Athlone, 101-116.

Beck, Ulrich (1992), Risk Society: Towards a New Modernity. London: Sage.

Beck, Ulrich (2000), Un nuevo mundo feliz: La precaridad del trabajo en la era da la globalización. Barcelona: Paidós.

Bezuidenhout, Andries (1999), "Towards Global Social Movement Unionism? Trade Union Responses to Globalization in South Africa”. Geneva: International Labour Organisation. Consultado em 11.07.2001 e disponível em: <www.ilo.org/public/ english/bureauc/inst/papers/2000/dp115/>.

Burawoy, Michael (1985), The Politics of Production. London: Verso.

Cerdeira, Maria da Conceição (1997), "A sindicalização portuguesa de 1974 a 1995”, Sociedade e Trabalho, 1, 46-53.

Estanque, Elísio (2002), "A reinvenção do sindicalismo e os novos desafios emancipatórios: do despotismo local à mobilização global”, in Boaventura de Sousa Santos (org.), Trabalhar o mundo: Os caminhos do novo internacionalismo operário. Rio de Janeiro: Editora Record (no prelo).

Estanque, Elísio; Mendes, José Manuel (1998), Classes e desigualdades sociais em Portugal - um estudo comparativo. Porto: Afrontamento.

Ferreira, António Casimiro (2001), "Para uma concepção decente e democrática do trabalho e dos seus direitos: (Re)pensar o direito das relações laborais", in Boaventura de Sousa Santos (org.), Globalização: Fatalidade ou utopia?. Porto: Afrontamento, 255-293.

Moody, Kim (1997), Workers in a Lean World: Unions in the International Economy. London: Verso.

Pakulsky, Jan; Waters, Malcolm (1996), The Death of Class. London: Sage. 
Santos, Boaventura de Sousa (1994), Pela mão de Alice. O social e o político na pós-modernidade. Porto: Afrontamento.

Santos, Boaventura de Sousa (1995), “Teses para a reinvenção do sindicalismo em Portugal, seguidas de um apelo", Vértice, 68, 132-139.

Santos, Boaventura de Sousa (2000), A crítica da razão indolente: Contra o desperdício da experiência. Porto: Afrontamento.

Wright, Erik Olin (1985), Classes. London: Verso.

Wright, Erik Olin (1997), Class Counts. Cambridge: Cambridge UP. 